\title{
Pediatric occipitocervical fixation: radiographic criteria, surgical technique, and clinical outcomes based on experience of a single surgeon
}

\author{
Eduardo Martinez-del-Campo, MD, Jay D. Turner, MD, PhD, Leonardo Rangel-Castilla, MD, \\ Hector Soriano-Baron, MD, Samuel Kalb, MD, and Nicholas Theodore, MD \\ Department of Neurosurgery, Barrow Neurological Institute, St. Joseph's Hospital and Medical Center, Phoenix, Arizona
}

OBJECTIVE If left untreated, occipitocervical (OC) instability may lead to serious neurological injury or death. Open internal fixation is often necessary to protect the neurovascular elements. This study reviews the etiologies for pediatric OC instability, analyzes the radiographic criteria for surgical intervention, discusses surgical fixation techniques, and evaluates long-term postoperative outcomes based on a single surgeon's experience.

METHODS The charts of all patients $<18$ years old who underwent internal $\mathrm{OC}$ fixation conducted by the senior author were retrospectively reviewed. Forty consecutive patients were identified for analysis. Patient demographic data, OC junction pathology, radiological diagnostic tools, surgical indications, and outcomes are reported.

RESULTS The study population consisted of 20 boys and 20 girls, with a mean age of 7.3 years. Trauma $(45 \%[n=18])$ was the most common cause of instability, followed by congenital etiologies (37.5\% [ $n=15])$. The condyle-C1 interval had a diagnostic sensitivity of $100 \%$ for atlantooccipital dislocation. The median number of fixated segments was 5 (occiput-C4). Structural bone grafts were used in all patients. Postsurgical neurological improvement was seen in $88.2 \%$ (15/17) of patients with chronic myelopathy and in 25\% (1/4) of patients with acute myelopathy. Preoperatively, $42.5 \%$ (17/40) of patients were neurologically intact and remained unchanged at last follow-up, $42.5 \%$ (17/40) had neurological improvement, $12.5 \%(5 / 40)$ remained unchanged, and $2.5 \%(1 / 40)$ deteriorated. All patients had successful fusion at 1-year follow-up. The complication rate was 7.5\% (3/40), including 1 case of vertebral artery injury.

CONCLUSIONS Occipitocervical fixation is safe in children and provides immediate immobilization, with excellent survival and arthrodesis rates. Of the radiographic tools evaluated, the condyle-C1 interval was the most predictive of atlantooccipital dislocation.

http://thejns.org/doi/abs/10.3171/2016.2.PEDS15544

KEY WORDS fusion; long-term; occipitocervical; outcome; pediatric; spine

J $\mathrm{F}$ F left untreated, occipitocervical (OC) instability can be a devastating condition. Internal fixation and ultimately fusion are often required to provide necessary stabilization. The indications for OC fixation in children and adults are similar. ${ }^{2}$ In the pediatric population, trauma and congenital abnormalities are the most common causes of OC instability. ${ }^{18,20,24-26,39,40,42,44,52,54,58}$ Upper cervical spine injuries account for $56 \%-73 \%$ of all cervical traumas and are twice as common in children as in adults..$^{24,39,42}$ Highenergy impacts, such as motor vehicle collisions, are most often responsible for the development of traumatic atlantooccipital dislocation (AOD) and atlantoaxial dislocation
(AAD). Atlantooccipital dislocation is associated with the highest mortality rate..$^{5,7,23,24,39-43,45,48}$ Congenital syndromes associated with OC instability include Klippel-Feil, Down syndrome, Morquio syndrome, neurofibromatosis, Conradi Hünermann syndrome, Goldenhar syndrome, and spondyloepiphyseal dysplasia. Developmental abnormalities associated with OC instability include Chiari malformations, syringomyelia, os odontoideum, and posterior arch rachischisis. ${ }^{2,11,12,15,25,31,32,54}$

Management of OC instability in the pediatric population has evolved in the past decade, from wiring techniques to screw-rod constructs. ${ }^{8,16}$ Results from recent biomechani-

ABBREVIATIONS $A A D=$ atlantoaxial dislocation; $A D I=$ atlantodental interval; $A I S=$ American Spinal Injury Association (ASIA) impairment scale; $A O D=$ atlantooccipital dislocation; $\mathrm{AVM}=$ arteriovenous malformation; $\mathrm{CCI}=$ condyle-C1 interval; $\mathrm{CVJ}=$ craniovertebral junction; $\mathrm{EDS}=$ Ehlers-Danlos syndrome; mJOAS = modified Japanese Orthopaedic Association score; NLI = neurological level of injury; OC = occipitocervical; OCF = occipitocervical fusion.

SUBMITTED September 4, 2015. ACCEPTED February 25, 2016.

INCLUDE WHEN CITING Published online June 10, 2016; DOI: 10.3171/2016.2.PEDS15544. 
cal and clinical studies suggest that fixation, using occipital keel screws, occiput-C1 transarticular screws, and $\mathrm{C} 1-2$ transarticular screws (with good screw purchase), provides the best immobilization and fusion rates. The incorporation of structural grafts strengthens the construct and improves arthrodesis rates. . $^{3,6,7,17,40,57}$ However, the most appropriate fixation strategy must be tailored to each patient; surgeons should consider the underlying pathology, size of the spinal osseous structures, any anatomical variations, and extent of pathology. The size of the bone at sites of fixation is most often dictated by the patient's age and any comorbid congenital syndrome. It is one of the most important considerations in determining a fixation strategy for the craniovertebral junction (CVJ) in children. When the bony fixation points are too small to accommodate screws, wiring techniques are most often used.

Long-term sequelae of OC internal fixation in children have been an area of concern. Adverse effects on spinal alignment, stability, and cervical spine growth have been described. . $^{3,14,15,27,36,40,49,57}$ Although several pediatric series on this topic have been previously published, ${ }^{10,15,23,24,36,41,57}$ results need to be interpreted cautiously because of relatively small sample sizes. ${ }^{3,4,12,17,26,36,38,39,44,49}$ To our knowledge, this study represents one of the largest single-surgeon case series to date describing OC fixation in the pediatric population.

\section{Methods}

The institutional review board at St. Joseph's Hospital and Medical Center (Phoenix, AZ) approved this study. Forty-three pediatric patients with a diagnosis of OC instability underwent OC fixation performed by the senior author (N.T.) between 2004 and 2013, at Barrow Neurological Institute (Phoenix, AZ). Three patients were excluded because of missing data, which left 40 patients for inclusion in this detailed retrospective analysis.

Trauma and relevant comorbidities were documented. Plain lateral and anteroposterior cervical radiographs, CT scans, 3D CT reconstructions, and MR images were used for pre- and postoperative radiological analysis. Etiologies for OC instability included trauma, congenital abnormalities, neoplasms, vascular malformations, and multiple causes (detailed in the Results section). Patients with preoperative neurological deficits were grouped into 2 cohorts according to the time course of symptom evolution. Patients with trauma formed the acute myelopathy cohort. The remainder of the patients, who had progressive evolution of symptoms, formed the chronic injury cohort. All patients were surgically treated on the basis of clinical presentation, radiographic evidence of OC instability, and the senior author's (N.T.) clinical judgment.

All patients were preoperatively immobilized in the neutral position as needed. When AOD was suspected, external immobilization was achieved by placing sandbags on each side of the patient's head and securing the head and sandbags to the bed with tape. Rigid cervical collars, which are potentially harmful with distraction injuries, were avoided. ${ }^{39,40}$ Halo vest orthoses were used in some cases when immediate operative intervention was not possible.

Patients who were diagnosed as having a minor injury to the $\mathrm{CVJ}$ that did not require $\mathrm{OCF}$ were not included in our analysis. Thus, the incidence of preoperative collar use was not assessed.

Surgical techniques and types of hardware were documented, along with the type of graft used. ${ }^{2,6,8,16,33}$ Use of external orthoses, if required, was documented before and after surgery. In patients with traumatic injuries and suspected AOD, the condyle-C1 interval (CCI) was used to confirm the diagnosis; for those with suspected AAD, the atlantodental interval (ADI) was used. ${ }^{41}$ Sagittal and coronal reconstructions of preoperative $\mathrm{CT}$ scans were used to determine the CCIs (Fig. 1). Four equidistant measurements were made for each occiput-C1 joint (labeled $\mathrm{CC} 1-\mathrm{CC} 4)$ at the point of longest contact to generate a mean CCI. A mean CCI $\geq 4 \mathrm{~mm}$ on either side was considered abnormal and indicative of AOD. ${ }^{42}$ The ADI was determined by measuring the distance from the posterior aspect of the anterior arch of C-1 to the anterior border of the dens, using either sagittal CT reconstructions or lateral radiographs. Flexion-extension radiographs were also obtained if static ADI was $<4 \mathrm{~mm}$ but positional instability was still suspected. Atlantoaxial instability was defined as an ADI $>4 \mathrm{~mm}$, or positional change in ADI $>4 \mathrm{~mm}^{5}$

Benzel et al.'s9 modified Japanese Orthopaedic Association score (mJOAS) and Hirabayoshi et al.'s ${ }^{22}$ recovery rate were used to assess clinical outcome results in patients with chronic injury preoperatively, postoperatively, and at last follow-up. The Hirabayashi recovery rate (RR) was calculated and used as a prognostic tool and an indicator of clinical outcome, using the formula: RR $=$ ([postoperative mJOAS - preoperative mJOAS]/preoperative mJOAS) $\times 100.55$

Spinal cord injury in patients with acute myelopathy was assessed with the American Spinal Injury Association (ASIA) impairment scale (AIS) preoperatively, postoperatively, and at last follow-up. Complete injury (AIS Grade A) is defined as no sensory or motor function preserved in S4-5 below the neurological level of injury (NLI). Sensory incomplete injury (AIS Grade B) is defined as sensory function but not motor function preserved below the NLI, including S4-5 and deep anal pressure. Motor incomplete (AIS Grade C) is defined as motor function preserved below the NLI, and more than half of key muscle functions below the NLI have strength scores $\leq 2$ out of 5 . Motor incomplete (AIS Grade D) is defined as motor function preserved below the NLI, and at least half of key muscle functions have strength scores $\geq 3$ out of 5 . Normal (AIS Grade E) is defined as neurologically intact (http://www. asia-spinalinjury.org/elearning/ASIA_ISCOS_high.pdf).

Neurological monitoring during surgery with somatosensory evoked potentials and motor evoked potentials was performed in all patients when technically feasible. Baseline tracings were obtained before positioning. ${ }^{40}$ Structural autografts were used to provide additional structural support and increase the area of arthrodesis. ${ }^{6}$ Most autografts were harvested from a posterior rib; most allografts were from a cadaveric fibula. The curvature of the posterior rib graft usually mirrors the curvature of the posterior $\mathrm{OC}$ junction; therefore, it was preferred when suitable. Fluoroscopy was used in all cases for assistance with positioning and intraoperative confirmation of hard- 

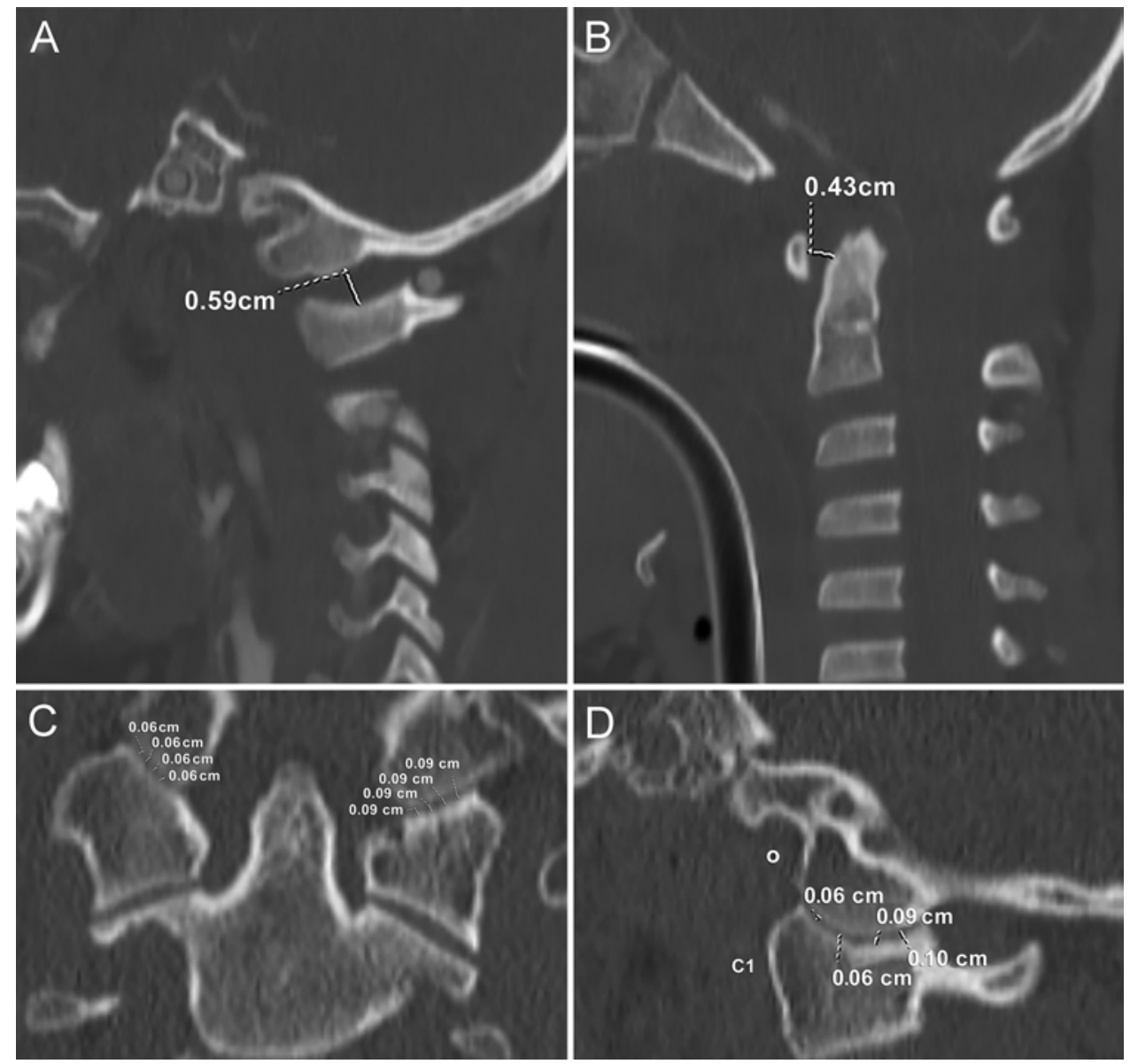

FIG. 1. A: Parasagittal CT image of the CVJ of a patient with $A O D(C C l 0.59 \mathrm{~cm})$. B: Midsagittal CT image of the CVJ of a patient with $\mathrm{OC}$ instability (ADI $0.43 \mathrm{~cm}$ ). Coronal (C) and parasagittal (D) CT images of a patient with a normal $\mathrm{CCl}(<4 \mathrm{~mm})$.

ware placement, and in some cases the O-arm Surgical Imaging System (Medtronic, Inc.) was used. Intraoperative image-guided navigation was used for surgical planning and hardware placement in most cases.

Postoperatively, all patients were placed in rigid cervical collars for a minimum of 8 weeks. External orthosis was discontinued on the basis of the quality of arthrodesis and clinical progress. Fusion was defined as osseous trabeculation throughout the instrumented OC levels evident on anteroposterior and lateral cervical spine radiographs, and on CT scans when indicated. All radiographs were reviewed by the senior author (N.T.) and by an independent neuroradiologist. Follow-up was ongoing with clinical and radiographic control. Complications were documented intraoperatively and during the early and delayed postoperative periods.

Confidence values were calculated for reported data (significant at $\mathrm{p}<0.05)$ with t-tests $(2$-tailed distribution, 2 -sample equal variance). Means and standard deviations are provided when appropriate.

\section{Results}

\section{Patient Characteristics}

\section{Demographic Data}

Twenty (50\%) patients were boys, and 20 (50\%) were girls, with a mean age of $7.3 \pm 4.4$ years (range 7 months to 16 years). The mean age of the 18 patients with acute traumatic injuries was $6.2 \pm 4.1$ years (range $2-16$ years), and the mean age of the other 22 patients, all of whom had chronic pathologies, was $7.7 \pm 4.7$ years (range 7 months to 16 years $)(\mathrm{p}=0.3)$.

\section{Etiology of OC Instability}

The etiologies of OC instability and the indications for surgical treatment are presented in Table 1. The most common cause of instability overall was trauma, which occurred in 18 (45\%) patients; occipitoatlantoaxial dislocation was the most often diagnosed instability. None of the patients with trauma had any additional comorbidities (e.g., Down syndrome) at the time of injury. Congenital etiologies were the indication for surgery in 15 (37.5\%) patients; Chiari Type I malformation was the most common in this subgroup. One patient with Chiari malformation also had Ehlers-Danlos syndrome (EDS). Hardware failure was the third most common indication for surgery ( 3 cases $[7.5 \%]$ ) and was associated with multiple primary diagnoses among patients referred from outside hospitals.

Other etiology categories included neoplasm, inflammatory arthropathy, vascular pathology, and multiple causes; each had 1 representative case. The patient with vascular pathology had a rare upper cervical spine meta- 
TABLE 1. Diagnosis of occipitocervical fusion

\begin{tabular}{lc}
\hline \multicolumn{1}{c}{ Detailed Diagnosis } & No. $(\%)$ \\
\hline Trauma & $18(45.0)$ \\
\hline Occipitoatlantoaxial dislocation & $13(32.5)$ \\
\hline Occipitoatlantal dislocation & $3(7.5)$ \\
\hline Atlantoaxial dislocation & $2(5.0)$ \\
\hline Congenital & $15(37.5)$ \\
\hline Chiari Type I malformation & $5(12.5)$ \\
\hline Multiple congenital causes & $3(7.5)$ \\
\hline Morquio syndrome & $2(5.0)$ \\
\hline Spondyloepiphyseal dysplasia & $2(5.0)$ \\
\hline Wolf-Hirschhorn syndrome & $1(2.5)$ \\
\hline Down syndrome & $1(2.5)$ \\
\hline VACTERL association & $1(2.5)$ \\
\hline Hardware failure & $3(7.5)$ \\
\hline Failed arthrodesis (outside hospitals) & $1(2.5)$ \\
\hline Redo of Chiari decompression & $1(2.5)$ \\
\hline After resection of neurofibroma (intra- \& extradural) & $1(2.5)$ \\
\hline After resection of yolk sac tumor & $1(2.5)$ \\
\hline Neoplasms & $1(2.5)$ \\
\hline C-2 osteoid osteoma & $1(2.5)$ \\
\hline Inflammatory arthropathies & \\
\hline Juvenile rheumatoid arthritis & \\
\hline Vascular pathology & \\
\hline Metameric AVM in upper cervical spine & \\
\hline Multiple causes & \\
\hline Chiari Type I malformation, Klippel-Feil, basilar invagi- \\
nation, \& juvenile rheumatoid arthritis
\end{tabular}

VACTERL = vertebral, anal atresia, cardiac, tracheal, esophageal, renal, and limb defects.

meric arteriovenous malformation (AVM) and presented for decompression, biopsy, and OC fixation. Two patients with $\mathrm{OC}$ instability were initially treated nonoperatively by placing a halo vest but subsequently required surgical stabilization due to the extent of their injuries (1 with AOD/AAD; and 1 with AOD, C-2 Type 2 fracture, and C5-6 dislocation). All other patients were initially managed surgically. No patients were treated with halo vest immobilization after surgery.

Of the 18 patients with traumatic injuries, only 2 presented with polytrauma, which in these 2 cases did not require emergency surgery by other services before the neurosurgical procedure. After admission to the emergency department, all patients with traumatic injuries were immediately transferred to the ICU. Mean arterial pressure was maintained at $>85 \mathrm{~mm} \mathrm{Hg}$, and patients were optimized hemodynamically and metabolically and cleared for surgery within 24 hours.

\section{Preoperative Neurological Function}

Seventeen $(42.5 \%)$ of the 40 patients presented as neurologically intact preoperatively $-12(70.6 \%)$ from the acute injury cohort and 5 (29.4\%) from the chronic injury cohort. All 17 patients remained unchanged through the last follow-up visit; therefore, they were excluded from the analysis of neurological improvement. Patients presented preoperatively with neck pain $(26[65 \%])$, weakness $(22$ [55\%]), bladder and/or bowel incontinence (17 [42.5\%]), numbness (12 [30\%]), gait ataxia (12 [30\%]), and quadriplegia (1 [2.5\%]) (Table 2). Five cases with unique clinical presentations, comorbidities, and evolution are summarized in Table 3.

Two of the 18 trauma patients presented with severe traumatic brain injury (Glasgow Coma Scale score of 3), were unfit to undergo motor function testing on admission, and had no additional neurological deficit after surgery; both were AIS D at last follow-up. Preoperatively, $75 \%(12 / 16)$ of our patients with trauma were neurologically intact, and none had vascular or cranial nerve injuries. Although only $25 \%(n=4)$ of patients with trauma presented with a neurological deficit, the neurological injuries that did occur were often severe; $75 \%(n=3)$ of those with a deficit were categorized as having AIS Grade A, B, or C impairment. Unlike patients with trauma, those with chronic injury were neurologically intact preoperatively in only $22.7 \%$ of cases $(5 / 22)$, probably because longer periods of myelopathy resulted in irreversible damage to the spinal cord.

\section{Diagnostic Radiological Measurements}

It was feasible to obtain ADI and CCI measurements retrospectively from 28 patients (mean age 7.2 years; range 8 months to 16 years). Atlantoaxial and occipitoatlantal dislocation correlated to an ADI $>4 \mathrm{~mm}$ in 5 of 15 (33.3\%) patients with suspected C1-2 instability and a CCI $>4 \mathrm{~mm}$ in all 16 patients with suspected occiput-C1 instability. The mean ADI was $3.2 \mathrm{~mm}$ (range $1.4-6.4 \mathrm{~mm}$ ), the mean right CCI was $3.7 \mathrm{~mm}$ (range 1.1-6.8 $\mathrm{mm}$ ), and the mean left CCI was $4.0 \mathrm{~mm}$ (range 1.3-6.1 mm). The ADI had a sensitivity of $17.6 \%$ for atlantoaxial instability, and CCI measurements had a sensitivity of $100 \%$ for AOD.

\section{Occipitocervical Fusion}

Types of Instrumentation

Threaded Steinmann pins and sublaminar wiring (Atlas Cable System, Medtronic Sofamor Danek USA, Inc.)

TABLE 2. Preoperative findings among acute and chronic injury cohorts

\begin{tabular}{|c|c|c|c|c|c|c|}
\hline \multirow[b]{2}{*}{ Symptoms } & \multicolumn{2}{|c|}{$\begin{array}{l}\text { Acute Injury } \\
\quad(n=18)\end{array}$} & \multicolumn{2}{|c|}{$\begin{array}{l}\text { Chronic Injury } \\
\quad(n=22)\end{array}$} & \multicolumn{2}{|c|}{ All $(N=40)$} \\
\hline & No. & $\%$ & No. & $\%$ & No. & $\%$ \\
\hline Neck pain & 11 & 61.1 & 15 & 68.2 & 26 & 65.0 \\
\hline Incontinence & 1 & 5.6 & 16 & 72.7 & 17 & 42.5 \\
\hline Weakness $(\leq 2 \text { of } 5)^{*}$ & 4 & 22.2 & 11 & 50.0 & 15 & 37.5 \\
\hline Altered reflexes & 2 & 11.1 & 12 & 54.5 & 14 & 35.0 \\
\hline Numbness & 1 & 5.6 & 11 & 50.0 & 12 & 30.0 \\
\hline Gait ataxia & 1 & 5.6 & 11 & 50.0 & 12 & 30.0 \\
\hline Weakness $(\geq 3 \text { of } 5)^{\star}$ & 1 & 5.6 & 6 & 27.3 & 7 & 17.5 \\
\hline Flaccidity & 1 & 5.6 & 0 & 0 & 1 & 2.5 \\
\hline Decreased rectal tone & 1 & 5.6 & 0 & 0 & 1 & 2.5 \\
\hline
\end{tabular}

* ASIA scale for strength $(0=$ no strength to $5=$ full strength $)$. 
TABLE 3. Relevant presentation, comorbidities, and evolution of 5 cases

\begin{tabular}{|c|c|c|c|c|}
\hline Case & Presentation & Preop & Postop & Last Follow-Up \\
\hline 1 & $\begin{array}{c}\text { Congenital, bilat VA occlusion, \& } \\
\text { bilat PICA distribution strokes }\end{array}$ & $\begin{array}{l}\text { Neck pain; sensation, UE numb; strength, } \\
\text { 5/5; others included bilat hand ataxia, } \\
\text { normal gait, no incontinence }\end{array}$ & $\begin{array}{l}\text { Decreasing pain; sensation, } \\
\text { normal; strength, 5/5; no } \\
\text { incontinence }\end{array}$ & $\begin{array}{l}\text { No pain; sensation, normal; } \\
\text { strength, } 5 / 5 \text {; no inconti- } \\
\text { nence }\end{array}$ \\
\hline 2 & $\begin{array}{l}\text { Upper cervical spine metameric } \\
\text { AVM, It hemispheric cerebro- } \\
\text { vascular accident secondary to } \\
\text { embolization, Cushing syndrome }\end{array}$ & $\begin{array}{l}\text { Excruciating neck pain, headache, \& } \\
\text { spastic movements; sensation, rt UE \& } \\
\text { rt LE numb; strength, rt UE } 2 / 5 \text { \& rt LE } \\
\text { 4-/5; no incontinence }\end{array}$ & $\begin{array}{l}\text { No pain; sensation, rt UE } \\
\text { \& rt LE 4-/5; strength, rt } \\
\text { UE } 3+/ 5 \text { \& rt LE numb; no } \\
\text { incontinence }\end{array}$ & $\begin{array}{l}\text { Mild neck pain; sensation, rt } \\
\text { UE \& rt LE 4+/5; strength, } \\
\text { rt UE } 4+/ 5 \text { \& rt LE numb; } \\
\text { no incontinence }\end{array}$ \\
\hline 3 & $\begin{array}{l}\text { Multiple congenital abnormalities, } \\
\text { hardware failure, spinal cord } \\
\text { tethering, suboccipital craniecto- } \\
\text { my, \& multiple VP shunt failures }\end{array}$ & $\begin{array}{l}90^{\circ} \text { kyphosis, dysphagia, rapidly progres- } \\
\text { sive myelopathy, pain; sensation, NA; } \\
\text { strength, } 2 / 5 \text {; incontinent }\end{array}$ & $\begin{array}{l}\text { Quadriplegic, GCS score } \\
\text { of 6; sensation, NA; } \\
\text { strength, withdraws all } \\
\text { extremities; incontinent, } \\
\text { frequent catheterization }\end{array}$ & $\begin{array}{l}\text { Quadriplegic, GCS score of } \\
\text { 8; sensation, NA; strength, } \\
\text { spontaneous extremity } \\
\text { movement; incontinent, } \\
\text { frequent catheterization }\end{array}$ \\
\hline 4 & Traumatic motor vehicle crash & $\begin{array}{l}\text { AIS A; sensation, UE normal \& LE none; } \\
\text { strength, UE } 2 / 5 \text { \& LE 0/5; incontinent }\end{array}$ & $\begin{array}{l}\text { AIS A; sensation, UE normal } \\
\text { \& LE none; strength, UE } \\
\text { 2/5 \& LE 0/5; incontinent }\end{array}$ & $\begin{array}{l}\text { AIS A; sensation, UE normal } \\
\text { \& LE none; strength, UE } \\
\text { 3+/5 \& LE 0/5; incontinent }\end{array}$ \\
\hline 5 & $\begin{array}{l}\text { Traumatic GLF, traumatic brain } \\
\text { injury }\end{array}$ & $\begin{array}{l}\text { GCS score of 3; sensation, NT; strength, } \\
\text { NT; deep anal pressure normal }\end{array}$ & $\begin{array}{l}\text { Mild pain, AIS D; sensation, } \\
\text { normal; strength, 4/5; no } \\
\text { incontinence }\end{array}$ & $\begin{array}{l}\text { No pain, AIS D; sensation, } \\
\text { normal; strength, 4+/5; no } \\
\text { incontinence }\end{array}$ \\
\hline
\end{tabular}

GCS = Glasgow Coma Scale; GLF = ground-level fall; LE = lower extremity; NA = not available; NT = not testable; PICA = posterior inferior cerebellar artery; UE = upper extremity; VA = vertebral artery; VP = ventriculoperitoneal.

were used in $20(50 \%)$ patients, screw-based constructs were used in $19(47.5 \%)$ patients, and a sutured structural autograft was used in 1 (2.5\%) 7-month-old patient. Neuronavigation was used in all patients undergoing placement of screw-based constructs. Multiple fixation systems, such as the Synthes Synapse system (Synthes, Inc.), Synthes Axon (Synthes, Inc.), and Medtronic Vertex (Medtronic, Inc.), were used. All patients were able to undergo intraoperative neuromonitoring, and no changes were noted in any case.

Most patients included in this series presented with severe and sometimes devastating injuries to the $\mathrm{OC}$ junction and cervical spine requiring extensive instrumentation to correct basal deformities and to improve stability. The median number of instrumented levels was 5 (from occiput to C-4 in 17 [42.5\%] cases), followed by 4 levels (from occiput to C-3 in 10 [25\%] cases). There were 2 occiput-C2 (5\%), 1 occiput-C5 (2.5\%), and 1 occiput-C6 $(2.5 \%)$ constructs. Among constructs extending to the thoracic spine, there were $6(15 \%)$ at occiput-T2 and $1(2.5 \%)$ each at occiput-T1, occiput-T3, and occiput-T4.

The 10 patients requiring instrumentation from occiput to $\mathrm{C}-3$ had injuries compromising bony or ligamentous structures extending to $\mathrm{C}$-2. In 17 cases involving instrumentation placed from the occiput to $\mathrm{C}-4,7$ patients (41.2\%) had injuries compromising structures extending at least to C-3. Two of the $17(11.8 \%)$ required tumor excision, hardware removal, and repeated occipitocervical fusion (OCF), and $8(47.1 \%)$ had severe congenital cervical abnormalities. The patient who underwent placement of occiput-C5 instrumentation had hardware removal and repeat $\mathrm{OCF}$ requiring extension of the instrumentation. The patient who underwent placement of occiput-C6 hardware had severe congenital cervical abnormalities.

All 9 of the patients with instrumentation extending to the thoracic spine and 2 patients with instrumentation extending to the lower cervical spine had occipitoatlantal, atlantoaxial, or occipitoatlantoaxial instability with additional abnormalities. These conditions included occiput-T2 instability with Morquio syndrome (2 patients), C5-6 and C6-7 (1 patient each) traumatic spondylolisthesis, C6-7 complete 3 -column injury (1 patient), metameric AVM obliteration and instrumentation extending from the occiput to T-2 (1 patient), multilevel intra- and extraaxial tumor excision (1 patient), severe congenital cervical abnormalities (3 patients), and severe kyphosis (1 patient).

\section{Patients With Arthrodesis}

Structural bone grafts were used in all patients, with grafts taken from a posterior rib in 39 of these patients and a fibular allograft used in 1 patient. Morcellized autograft and/or allograft bone was placed posterolaterally over the decorticated CVJ in all patients.

\section{Decompression Procedures}

Decompression of the neural elements was performed in $14(35 \%)$ patients. Procedures included laminectomies, suboccipital craniectomies, corpectomies, hardware removal, and tumor/mass resections.

\section{Outcome Measures}

\section{Clinical and Radiographic Follow-Up}

The mean clinical and radiographic follow-up was 31.9 months (range 16-119 months). Preoperatively, 42.5\% (17/40) of patients were neurologically intact and remained unchanged at last follow-up, $42.5 \%$ (17/40) had neurological improvement, $12.5 \%$ (5/40) remained unchanged, and $2.5 \%(1 / 40)$ deteriorated. Follow-up is ongoing.

\section{Chronic Injury}

Neurological outcome was assessed in all patients with 
chronic myelopathy by use of the mJOAS and the recovery rate. A total of 17 patients were included in the analysis (Table 4). The first clinical follow-up for all patients occurred between 2 and 8 weeks postoperatively, and the last follow-up for patients with chronic injuries occurred at a mean $28.3 \pm 12$ months postoperatively. Six $(35.3 \%)$ patients had regained full neurological function at last follow-up. The mean mJOAS improved from $10.9 \pm 4.2$ (range 4-17 points) preoperatively to $14.0 \pm 4.3$ (range $3-18$ points) postoperatively $(\mathrm{p}<0.001)$, and to $13.9 \pm 4.5$ (range 3-18 points) at last follow-up. The recovery rate was $20.8 \%$ postoperatively and $20.6 \%$ at last follow-up (p $=0.3)$.

\section{Acute Injury}

Four patients with traumatic spinal cord injury were included in the outcome analysis of acute myelopathy. Three patients presented with incomplete spinal cord injury (1 each with AIS Grade B, C, and D), and 1 patient presented with complete spinal cord injury (AIS Grade A). The patient with AIS Grade B impairment improved 1 categorical grade postoperatively. The status of each of the remaining 3 patients was unchanged at last follow-up. Two patients with acute myelopathy had a severe traumatic brain injury, which limited complete assessment of spinal cord injury with the AIS; those patients were excluded from the analysis.

\section{Arthrodesis Results}

Successful fusion was confirmed in all patients in the series by use of lateral flexion-extension and anteroposterior radiographs and CT scans between 4 months and 1 year after surgery.

\section{Incidence of Complications}

Complications occurred in 3 patients (7.5\%) (Table 5). There were 2 intraoperative complications and 2 postoperative complications.

One patient had a left vertebral artery injury during placement of a C-1 lateral mass screw, which caused a dissecting aneurysm of the vertebrobasilar junction. During the placement of the $\mathrm{C}-1$ lateral mass screw and immedi-

TABLE 4. Chronic injury clinical improvement among 17 patients

\begin{tabular}{lcc}
\hline \multirow{1}{*}{$\begin{array}{c}\text { Neurological Status by } \\
\text { Change in mJOAS }\end{array}$} & \multicolumn{2}{c}{ No. of Patients (\%) } \\
\cline { 2 - 3 } & Postop Follow-Up* & Last Follow-Up† \\
\hline Intact (18 points) & $4(23.5)$ & $6(35.3)$ \\
\hline Declined & $1(5.9)$ & $1(5.9)$ \\
\hline $\begin{array}{l}\text { Unchanged (mJOAS other than } \\
18 \text { points) }\end{array}$ & $1(5.9)$ & $1(5.9)$ \\
\hline $\begin{array}{l}\text { Improved } \\
1 \text { point }\end{array}$ & $15(88.2)$ & $15(88.2)$ \\
\hline 2 points & $1(5.9)$ & $1(5.9)$ \\
\hline 3 points & $3(17.6)$ & $4(23.5)$ \\
\hline 4 points & $5(29.4)$ & $5(29.4)$ \\
\hline 2 points & $3(17.6)$ & $2(11.8)$ \\
\hline
\end{tabular}

* Postoperative follow-up occurred between 2 and 8 weeks after surgery.

$\dagger$ Final follow-up was a mean $28.3 \pm 12$ months postoperatively. ately after the dissection was identified, the hemorrhage was contained by completing the screw placement and placing wax around the screw. No Surgicel or Surgifoam (Ethicon) nor any other prothrombotic agent was used at that time because the hemorrhage ceased immediately. During this event, the patient suffered bradycardia and hypertension, which were managed promptly by the anesthesiologist. The occiput-C4 screw-rod system was secured, precluding the placement of the contralateral C-1 screw, and the surgery was terminated on an emergency basis. The patient was rushed to radiology for a CT angiogram, which showed flow cessation of the left vertebral artery, brainstem stroke, and basilar subarachnoid hemorrhage. Postoperative embolization of the left vertebral artery dissecting aneurysm was performed; however, the patient did not improve and had a devastating neurological outcome.

In the second intraoperative complication, the patient had a traumatic pneumothorax during rib harvest. Two months postoperatively, this patient also developed wound dehiscence, which was managed conservatively.

The second postoperative complication occurred in a third patient. This patient had a delayed complication of a dehiscent and infected wound, which required open debridement.

\section{Discussion \\ Demographic Data}

Our study contained an equal proportion of male and female patients, which contrasts with previously reported ratios ranging from $1.5: 1$ to $3: 1$ for male-to-female ratios. The mean age of 7.3 years is similar to other reports, in which ages ranged from 5.2 to 9 years..$^{5,11,20,25,26,39,48}$

\section{Etiology of OC Instability}

Occipitocervical instability results from the disruption of normal osseous and ligamentous structures. This damage can be caused by trauma or by anatomical variations due to several underlying abnormal conditions. Trauma represented the most common cause of OC instability in this series (45\% of cases). Although traumatic OC destabilization occurs in all age groups, young children $(<8$ years) are especially vulnerable due to hypermobility of the CVJ and increased head-to-torso size and weight ratios. ${ }^{7,25,27,39,48}$ Although in the present study the mean age of patients with acute traumatic injuries $(6.2 \pm 4.1$ years; range $2-16$ years) differed from that of those with all other chronic pathologies $(7.7 \pm 4.7$ years; range 7 months to 16 years), this difference was not statistically significant $(\mathrm{p}=0.3)$. Both traumatic $\mathrm{c}^{17,24,26,48}$ and congenital etiologies ${ }^{12,20,25,44,52,57}$ are frequently reported as the most common causes of OC instability in children.

Bollo et al. ${ }^{10}$ reported an association between posterior fossa decompression for Chiari malformations and $\mathrm{OCF}$, with $6 \%$ of patients requiring OCF after decompression due to medullary kinking, odontoid process retroflexion, and basilar invagination. Some authors have proposed a relationship between EDS and OC instability, ${ }^{19,35,50}$ due to inherent joint hyperlaxity in patients with EDS. However, a clear association between either AOD or AAD and EDS has not yet been established. We had 1 patient with a his- 
TABLE 5. Operative and postoperative complications

\begin{tabular}{|c|c|c|c|c|}
\hline Case & Complication(s) & Initial Surgery & Etiology & Description, Management, \& Sequelae \\
\hline A & VA injury & Occiput-C4 & Congenital & $\begin{array}{l}\text { Lt VA injured during C-1 lateral mass screw placement, } \\
\text { resulting in vessel occlusion; management, It VA emboliza- } \\
\text { tion; sequelae included brainstem infarction, basilar SAH, } \\
\text { quadriplegia, locked-in syndrome, \& death } 18 \text { mos postop }\end{array}$ \\
\hline \multirow[t]{2}{*}{$B$} & Traumatic pneumothorax & Occiput-C4 & Congenital & $\begin{array}{l}\text { Traumatic pneumothorax during rib harvest; management, } \\
\text { chest tube placement; sequelae, none }\end{array}$ \\
\hline & Wound dehiscence & & & $\begin{array}{l}\text { Dehiscence of posterior OC wound } 2 \text { mos postop; manage- } \\
\text { ment, conservative; sequelae, none }\end{array}$ \\
\hline $\mathrm{C}$ & Wound dehiscence & Occiput-T4 & Congenital & $\begin{array}{l}\text { Superficial breakdown of incision } 7 \text { mos postop; management } \\
\text { included open debridement \& antibiotics; sequelae, none }\end{array}$ \\
\hline
\end{tabular}

SAH = subarachnoid hemorrhage.

tory of Chiari malformation and EDS who developed progressive neurological deterioration and signs of myelopathy, leading to suspicion of occipitoatlantoaxial dislocation and incomplete spinal cord injury. However, the relative contributions of the Chiari malformation and EDS to the patient's instability are unknown.

\section{Diagnostic Radiological Measurements}

Detailed imaging of the OC junction is essential in cases of suspected OC instability. The ADI measurement is a radiographic tool that is used to evaluate the integrity of the atlantodental, alar, and transverse ligaments, and, in turn, OC stability. A static ADI $\geq 4 \mathrm{~mm}$ is consistent with AAD and OC instability. However, even in an unstable CVJ, neutral radiographs may show a normal ADI $(<4 \mathrm{~mm})$; in this setting, dynamic imaging with flexionextension views is required to establish the diagnosis. An $\mathrm{ADI} \geq 4 \mathrm{~mm}$ in any position is considered consistent with atlantoaxial instability. ${ }^{50}$

The CCI measurement is considered an excellent tool for radiological diagnosis of AOD..$^{5,39,41,50}$ Other diagnostic

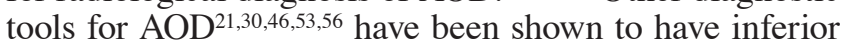
power compared with the CCI in the pediatric population. ${ }^{41,42}$ Our results support previously published data showing that the CCI has excellent diagnostic sensitivity and negative predictive value for AOD in pediatric patients. ${ }^{41}$

\section{Preoperative Neurological Function}

Neurological deficits in children who survive highenergy traumas to the CVJ are usually partial or absent, and may be associated with cranial nerve (most commonly abducens and hypoglossal nerves) $)^{1,5,29,37,43}$ and vertebral artery injuries. ${ }^{39,42}$ Survival rates after AOD, occipitoatlantoaxial dislocation, and AAD range from $39 \%$ to $63 \% ., 23,28$

\section{Surgical Planning}

Detailed imaging of the CVJ is essential for the surgical planning of OC fixation. Imaging allows for a complete understanding of the patient's anatomy and the consideration of any anatomical variations. An understanding of the size and interrelationship of the osseous structures dictates the instrumentation strategy. For example, smaller and less ossified vertebral bodies are often unable to accommodate screws, and wiring techniques should be used. Up to $25 \%$ of patients have unfavorable vertebral artery anatomy for screw placement. In some cases, 3D models of the spine have been used to assess the appropriateness of screw placement. ${ }^{13,57}$ Intraoperative image guidance with neuronavigation is becoming more common and is especially useful in pediatric patients with diminutive anatomy. Safe placement has been reported in up to $93 \%$ of pediatric patients, even in those with anatomy that might otherwise appear to preclude screw instrumentation. ${ }^{40,47}$ We found neuronavigation especially helpful in patients with severe congenital cervical abnormalities or a small osseous anatomy, as well as for orientation and assessment of adequate screw placement. Neuronavigation can also be very helpful for determining the midline and optimal placement of keel screws. Neurophysiological monitoring also serves as an important adjunct and is recommended in all cases. ${ }^{40,47}$

\section{Fixation Techniques}

An almost equal proportion of wire- and screw-based constructs was used in this case series (50\% vs $47.5 \%$ ) (Figs. 2-4). The decision to use either one was carefully determined on the basis of each individual's presentation, age, and bony anatomy, as well as on the basis of its technical feasibility and the surgeon's experience. The 7-monthold patient required special consideration and underwent fixation using a posterior rib structural autograft sutured to the CVJ due to the inability to place screws and sublaminar wiring.

As experience has continuously increased, the senior author now uses screw-rod and structural autograft constructs as the preferred method of fixation in appropriate patients because of their proven safety and effectiveness. In a systematic review by Hwang et al. ${ }^{25}$ of 285 patients with OCF, including 20 patients from their experience, a slight predilection was found for screw $(55.1 \%)$ versus wiring constructs (44.9\%). Our youngest patient with safe placement of screw-based constructs was 3 years old. Patients as young as $15-18$ months were reported to have screw fixation by Anderson et al. ${ }^{3,4}$ and Gluf and Brockmeyer. ${ }^{17}$

The use of short constructs (2-3 levels) has been most frequently reported in the literature. ${ }^{3,7,15,26}$ Longer constructs are sometimes needed to correct complex deformities and for patients with complicated presentations and 


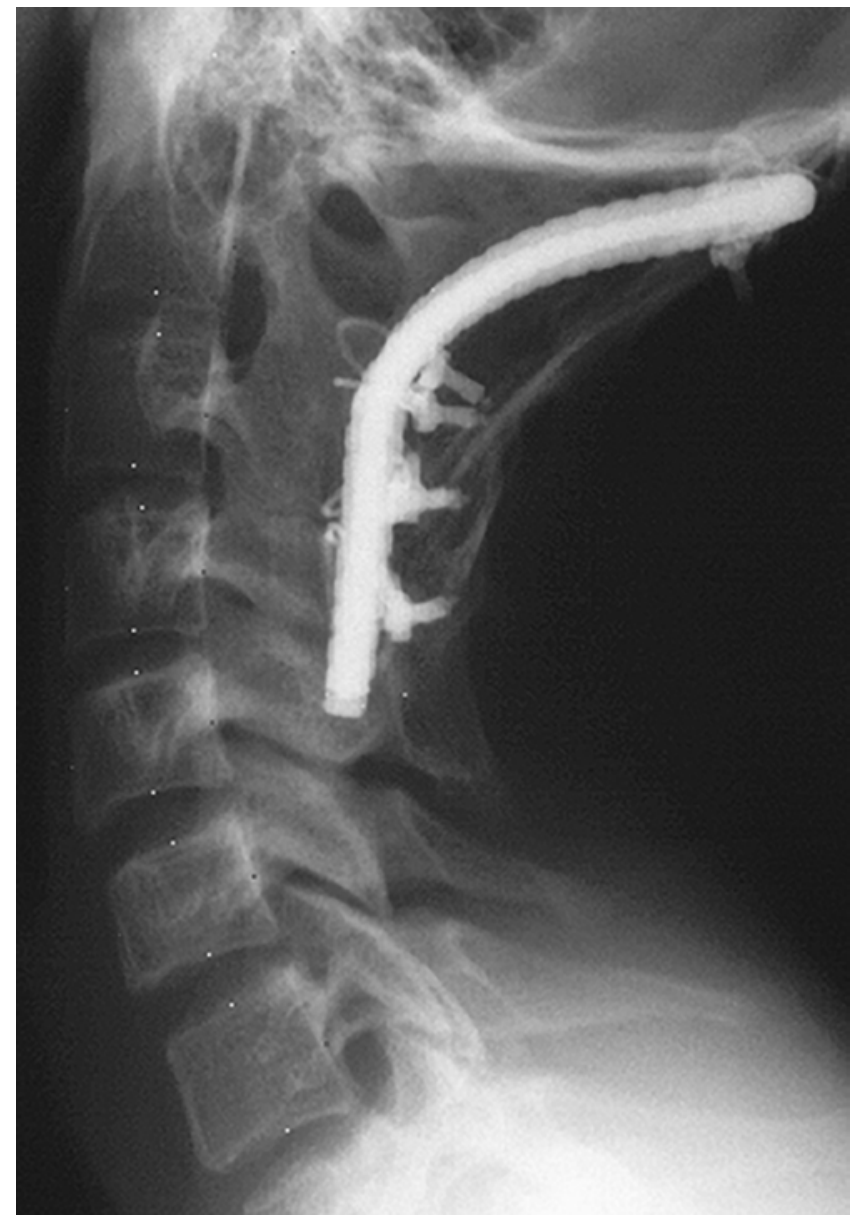

FIG. 2. Cervical lateral radiograph of a 7-year-old girl who underwent Steinmann pin fixation, sublaminar wiring extending from the occiput to C-4, and placement of a posterior rib structural autograft.

multilevel pathologies. Such was the case in the majority of our patients. The most frequent construct length in our series was occiput-C4 (42.5\%), and the longest construct required a total of 12 levels. Structural autografts are widely used in children ${ }^{2,11,12,15,17,25,34,48,52}$ to confer superior biomechanical rigidity across the CVJ (where joint surface arthrodesis is not readily attainable) and to provide structural support across the most mobile junction in the spine. Furthermore, the combined cortical/cancellous autografts possess ideal osteogenic, osteoinductive, and osteoconductive properties for the promotion of arthrodesis. ${ }^{6}$ Morcellized autograft/allograft was used in all patients in this series to augment fusion. Posterior rib harvest was favored due to much lower harvest-site morbidity, according to the senior author's experience. The size and shape of the rib are also ideally suited for the anatomy of the CVJ.,23,51 Augmentation with recombinant human bone morphogenetic protein was not performed in any of the patients in this series. Concern about the risks of recombinant human bone morphogenetic protein (e.g., heterotopic bone formation, osteolysis, neoplasia, and the paucity of published literature regarding its use in the pediatric population) was believed to outweigh the potential benefit of its use for this procedure in a pediatric population..$^{12,25}$

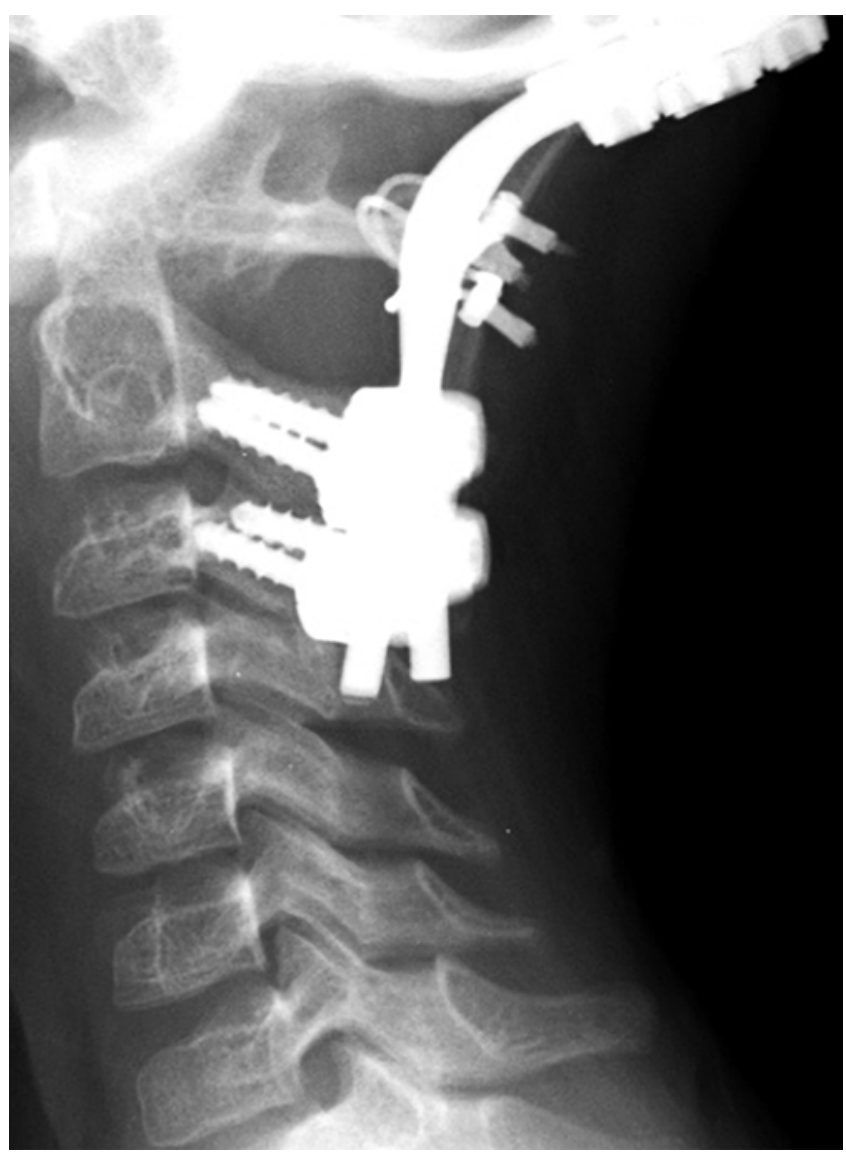

FIG. 3. Cervical lateral radiograph of a 10 -year-old boy in whom a screw-rod construct extends from the occiput to C-3, with occipital keel screws and lateral mass screws in C2-3.

\section{Clinical Outcomes}

The recovery rate for patients with chronic myelopathy was almost $21 \%$, with neurological improvement in $88.2 \%$ of 17 patients. Of the patients who had neurological improvement, $35.3 \%$ regained complete neurological function and 58.8\% improved 3-10 categorical points. One (5.9\%) patient remained unchanged. Twelve of the 18 patients with trauma were neurologically intact on admission, and only 1 of the 4 patients with initial spinal cord injury showed any improvement. Patients with complete spinal cord injury tended to remain unchanged despite surgical intervention.

The overall survival rate was $100 \%$ up to 1 year after the surgery, with $42.5 \%$ (17/40) of patients having significant neurological improvement and the same proportion $(42.5 \%, 17 / 40)$ remaining neurologically intact. Overall, $1(2.5 \%)$ patient deteriorated (chronic myelopathy), and 5 $(12.5 \%)$ remained unchanged. In contrast, Astur et al. ${ }^{5}$ reported neurological impairment in 50\% of their patients on the first follow-up; their result was similar to that of Labbe et al. ${ }^{28}$ who reported that one-half of their patients had persistent neurological deficits (mostly hemiparesis or hemiplegia).

Successful OCF rates in children have been reported as ranging from $84 \%$ to $100 \% .2,3,5,10,17,20,24,27,33$ In a systematic review of 285 patients, Hwang et al. ${ }^{25}$ found that in 


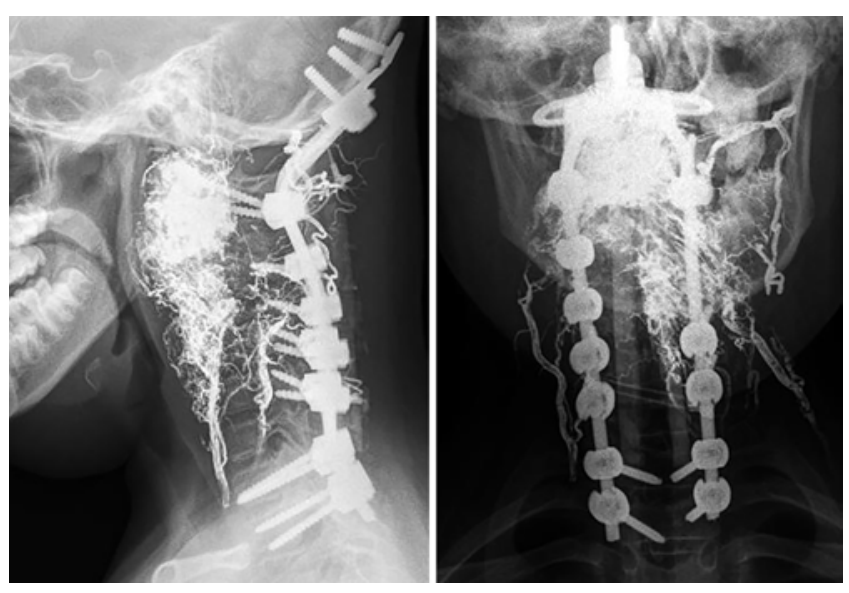

FIG. 4. Lateral (left) and anteroposterior (right) radiographs of the cervical spine of a 10 -year-old girl with a primary diagnosis of metameric AVM obtained after embolization, AVM resection, and spinal decompression and fusion with bilateral rods and screws from the occiput to T-2.

those with screw constructs, the fusion rate was $99 \%$ after 3 months, and that in patients with wire constructs, the rate was $95 \%$ (94.4\% overall average); the difference was not statistically significant. Radiological confirmation of fusion for both screw- and wire-based techniques in our series was $100 \%$ within the 1st year after surgery. The mean clinical and radiographic follow-up was 31.9 months (range 16-119 months).

External orthotics were used postoperatively to ensure rigid mobilization and to optimize fusion. Rigid collars are most often used, but halo vests or Minerva jackets can also be applied..$^{5,12,20,26} \mathrm{~A}$ radiological analysis of the curvature, alignment, and growth of patients included in this case series (18 of 40 patients; Martinez-del-Campo et al., our unpublished data, 2014) was done immediately after surgery and at the last follow-up. The results show that vertical and longitudinal growth continues after long-term follow-up in the instrumented levels and that there is not a statistically significant change in cervical curvature or alignment.

It is our opinion that adequate patient selection into different fixation modalities contributed to our fusion success rate. No patients required postoperative placement of a halo vest. External orthotics were sufficient to provide and ensure postoperative rigid mobilization and to optimize fusion. All of our patients used a rigid collar for 8 weeks postoperatively, or until fusion was confirmed.

\section{Complication Rates}

Complication rates of $\mathrm{OC}$ fixation reported in the literature range from $7.8 \%$ to $26 \%{ }^{20,25}$ Complications related to wiring techniques are usually more serious and frequent than those related to screw-based techniques $(50 \%$ vs $14 \%$, respectively). Wiring has the same complications as screwbased techniques, including graft resorption, unintended extension of fusion, hardware failure, quadriparesis, and death. ${ }^{25}$ Vertebral artery lesions have been described in $1.6 \%-4 \%$ of cases, ${ }^{12,17,20,25}$ hardware failure in up to $31 \%,{ }^{40}$ transverse sinus injuries in $10 \%,{ }^{24}$ pseudarthrosis in $10 \%,{ }^{24}$
CSF leak in $7.1 \%-15 \%, 5,24,26$ hydrocephalus in $28.6 \%, 5$ neurological deterioration in $50 \%, 5$ surgical reintervention in $10 \%-13.6 \%,{ }^{12,26}$ rib donor-site morbidity in $3.7 \%,{ }^{51}$ pseudomeningocele in $5 \%,{ }^{10}$ and death in 3.6\%-10\%. ${ }^{9}$ These rates were obtained from the reviewed literature, when readily available.

Other complications are wound problems (dehiscence, nonunion, and infection), graft resorption, fusion failure and extension, subfascial fluid collection, airway/respiratory problems, dysphagia/vocal cord paresis, and quadriparesis/quadriplegia. $., 3,5,10,12,17,20,24-26,33,36,40,57$ The overall complication rate in this series was comparable to what has been previously reported in the literature (7.5\%). Our rates were consistent with previous reports for vertebral artery injury $(2.5 \%), 2,3,5,12,17,20,24,39,57$ pneumothorax after rib harvest $(2.5 \%),{ }^{2,15,33,51}$ and issues with wound healing $\left.(2.5 \%)\right)^{2,5,24}$, $26,33,36$

\section{Study Limitations}

This study contains all of the inherent limitations of a single-surgeon, retrospective case series. Clinical and radiographic follow-up in these patients is ongoing, and the durability of the results will need to be reassessed as follow-up continues.

\section{Conclusions}

Pediatric patients with $\mathrm{OC}$ instability are at high risk for neurological devastation; these patients benefit from early and definitive treatment. In children, OC instability that requires surgical fixation is most often caused by either trauma or congenital conditions. If there is suspicion of OC instability, a complete diagnostic workup is warranted. The diagnosis can most often be established with a combination of CT, MRI, and/or dynamic radiography. In patients with an unstable CVJ, surgical fixation is indicated. Fixation strategies have evolved as newer technologies have become available. Screw-rod constructs have been demonstrated to be safe and effective, and their use has become increasingly popular.

A screw-rod construct combined with a structural autograft is now the preferred fixation strategy of the senior author in patients for whom it is appropriate. However, for patients with small osseous structures, poor bone quality, and/or unique anatomical relationships, screw-rod constructs may not be appropriate and alternative fixation strategies, such as sublaminar wiring, need to be considered. Long-term follow-up supports favorable clinical and radiographic outcomes. In experienced hands, OC fixation has been demonstrated to be a safe and effective means of treating OC instability and preserving neurological function in pediatric patients.

\section{References}

1. Abumi K, Shono Y, Ito M, Taneichi H, Kotani Y, Kaneda $\mathrm{K}$ : Complications of pedicle screw fixation in reconstructive surgery of the cervical spine. Spine (Phila Pa 1976) 25:962969,2000

2. Ahmed R, Traynelis VC, Menezes AH: Fusions at the craniovertebral junction. Childs Nerv Syst 24:1209-1224, 2008

3. Anderson RC, Kan P, Gluf WM, Brockmeyer DL: Long-term 
maintenance of cervical alignment after occipitocervical and atlantoaxial screw fixation in young children. J Neurosurg 105 (1 Suppl):55-61, 2006

4. Anderson RC, Ragel BT, Mocco J, Bohman LE, Brockmeyer DL: Selection of a rigid internal fixation construct for stabilization at the craniovertebral junction in pediatric patients. J Neurosurg 107 (1 Suppl):36-42, 2007

5. Astur N, Klimo P Jr, Sawyer JR, Kelly DM, Muhlbauer MS, Warner WC Jr: Traumatic atlanto-occipital dislocation in children: evaluation, treatment, and outcomes. J Bone Joint Surg Am 95:e194, 2013

6. Bambakidis NC, Feiz-Erfan I, Horn EM, Gonzalez LF, Baek $\mathrm{S}$, Yüksel KZ, et al: Biomechanical comparison of occipitoatlantal screw fixation techniques. J Neurosurg Spine 8:143-152, 2008

7. Baron EM, Loftus CM, Vaccaro AR, Dominique DA: Anterior approach to the subaxial cervical spine in children: a brief review. Neurosurg Focus 20(2):E4, 2006

8. Benke M, Yu WD, Peden SC, O'Brien JR: Occipitocervical junction: imaging, pathology, instrumentation. Am J Orthop 40:E205-E215, 2011

9. Benzel EC, Lancon J, Kesterson L, Hadden T: Cervical laminectomy and dentate ligament section for cervical spondylotic myelopathy. J Spinal Disord 4:286-295, 1991

10. Bollo RJ, Riva-Cambrin J, Brockmeyer MM, Brockmeyer DL: Complex Chiari malformations in children: an analysis of preoperative risk factors for occipitocervical fusion. $\mathbf{J}$ Neurosurg Pediatr 10:134-141, 2012

11. Brockmeyer DL, Brockmeyer MM, Bragg T: Atlantal hemirings and craniocervical instability: identification, clinical characteristics, and management. J Neurosurg Pediatr 8:357-362, 2011

12. Couture D, Avery N, Brockmeyer DL: Occipitocervical instrumentation in the pediatric population using a custom loop construct: initial results and long-term follow-up experience. J Neurosurg Pediatr 5:285-291, 2010

13. D'Urso PS, Askin G, Earwaker JS, Merry GS, Thompson RG, Barker TM, et al: Spinal biomodeling. Spine (Phila Pa 1976) 24:1247-1251, 1999

14. Dubousset J, Herring JA, Shufflebarger H: The crankshaft phenomenon. J Pediatr Orthop 9:541-550, 1989

15. Fargen KM, Anderson RC, Harter DH, Angevine PD, Coon VC, Brockmeyer DL, et al: Occipitocervicothoracic stabilization in pediatric patients. J Neurosurg Pediatr 8:57-62, 2011

16. Garrido BJ, Sasso RC: Occipitocervical fusion. Orthop Clin North Am 43:1-9, vii, 2012

17. Gluf WM, Brockmeyer DL: Atlantoaxial transarticular screw fixation: a review of surgical indications, fusion rate, complications, and lessons learned in 67 pediatric patients. J Neurosurg Spine 2:164-169, 2005

18. Gluf WM, Schmidt MH, Apfelbaum RI: Atlantoaxial transarticular screw fixation: a review of surgical indications, fusion rate, complications, and lessons learned in 191 adult patients. J Neurosurg Spine 2:155-163, 2005

19. Halko GJ, Cobb R, Abeles M: Patients with type IV EhlersDanlos syndrome may be predisposed to atlantoaxial subluxation. J R heumatol 22:2152-2155, 1995

20. Hankinson TC, Avellino AM, Harter D, Jea A, Lew S, Pincus $\mathrm{D}$, et al: Equivalence of fusion rates after rigid internal fixation of the occiput to $\mathrm{C}-2$ with or without $\mathrm{C}-1$ instrumentation. J Neurosurg Pediatr 5:380-384, 2010

21. Harris JH Jr, Carson GC, Wagner LK, Kerr N: Radiologic diagnosis of traumatic occipitovertebral dissociation: 2 . Comparison of three methods of detecting occipitovertebral relationships on lateral radiographs of supine subjects. AJR Am J Roentgenol 162:887-892, 1994

22. Hirabayashi K, Miyakawa J, Satomi K, Maruyama T, Wakano K: Operative results and postoperative progression of ossification among patients with ossification of cervical posterior longitudinal ligament. Spine (Phila Pa 1976) 6:354-364, 1981

23. Horn EM, Feiz-Erfan I, Lekovic GP, Dickman CA, Sonntag VK, Theodore N: Survivors of occipitoatlantal dislocation injuries: imaging and clinical correlates. J Neurosurg Spine 6:113-120, 2007

24. Hwang SW, Gressot LV, Chern JJ, Relyea K, Jea A: Complications of occipital screw placement for occipitocervical fusion in children. J Neurosurg Pediatr 9:586-593, 2012

25. Hwang SW, Gressot LV, Rangel-Castilla L, Whitehead WE, Curry DJ, Bollo RJ, et al: Outcomes of instrumented fusion in the pediatric cervical spine. J Neurosurg Spine 17:397409, 2012

26. Klimo P Jr, Astur N, Gabrick K, Warner WC Jr, Muhlbauer MS: Occipitocervical fusion using a contoured rod and wire construct in children: a reappraisal of a vintage technique. $\mathbf{J}$ Neurosurg Pediatr 11:160-169, 2013

27. Kosnik-Infinger L, Glazier SS, Frankel BM: Occipital condyle to cervical spine fixation in the pediatric population. $\mathbf{J}$ Neurosurg Pediatr 13:45-53, 2014

28. Labbe JL, Leclair O, Duparc B: Traumatic atlanto-occipital dislocation with survival in children. J Pediatr Orthop B 10:319-327, 2001

29. Lall R, Patel NJ, Resnick DK: A review of complications associated with craniocervical fusion surgery. Neurosurgery 67:1396-1403, 2010

30. Lee C, Woodring JH, Goldstein SJ, Daniel TL, Young AB, Tibbs PA: Evaluation of traumatic atlantooccipital dislocations. AJNR Am J Neuroradiol 8:19-26, 1987

31. Lowry DW, Pollack IF, Clyde B, Albright AL, Adelson PD: Upper cervical spine fusion in the pediatric population. $\mathbf{J}$ Neurosurg 87:671-676, 1997

32. Martirosyan NL, Cavalcanti DD, Kalani MY, Maughan PH, Theodore N: Aplasia of the anterior arch of atlas associated with multiple congenital disorders: case report. Neurosurgery 69:E1317-E1320, 2011

33. Menezes AH: Craniocervical fusions in children. J Neurosurg Pediatr 9:573-585, 2012

34. Menezes AH, Traynelis VC: Anatomy and biomechanics of normal craniovertebral junction (a) and biomechanics of stabilization (b). Childs Nerv Syst 24:1091-1100, 2008

35. Milhorat TH, Bolognese PA, Nishikawa M, McDonnell NB, Francomano CA: Syndrome of occipitoatlantoaxial hypermobility, cranial settling, and Chiari malformation type I in patients with hereditary disorders of connective tissue. J Neurosurg Spine 7:601-609, 2007

36. Moorthy RK, Rajshekhar V: Changes in cervical spine curvature in pediatric patients following occipitocervical fusion. Childs Nerv Syst 25:961-967, 2009

37. Mummaneni PV, Haid RW, Traynelis VC, Sasso RC, Subach BR, Fiore AJ, et al: Posterior cervical fixation using a new polyaxial screw and rod system: technique and surgical results. Neurosurg Focus 12(1):E8, 2002

38. Nakagawa T, Yone K, Sakou T, Yanase M: Occipitocervical fusion with C1 laminectomy in children. Spine (Phila Pa 1976) 22:1209-1214, 1997

39. Oppenlander ME, Clark JC, Sonntag VK, Theodore N: Pediatric craniovertebral junction trauma. Adv Tech Stand Neurosurg 40:333-353, 2014

40. Oppenlander ME, Kalyvas J, Sonntag VK, Theodore N: Technical advances in pediatric craniovertebral junction surgery. Adv Tech Stand Neurosurg 40:201-213, 2014

41. Pang D, Nemzek WR, Zovickian J: Atlanto-occipital dislocation-part 2: The clinical use of (occipital) condyle-C1 interval, comparison with other diagnostic methods, and the manifestation, management, and outcome of atlanto-occipital dislocation in children. Neurosurgery 61:995-1015, 2007

42. Pang D, Nemzek WR, Zovickian J: Atlanto-occipital disloca- 
tion: part 1-normal occipital condyle-C1 interval in 89 children. Neurosurgery 61:514-521, 2007

43. Papadopoulos SM, Dickman CA, Sonntag VK, Rekate HL, Spetzler RF: Traumatic atlantooccipital dislocation with survival. Neurosurgery 28:574-579, 1991

44. Parisini P, Di Silvestre M, Greggi T, Bianchi G: C1-C2 posterior fusion in growing patients: long-term follow-up. Spine (Phila Pa 1976) 28:566-572, 2003

45. Patel JC, Tepas JJ III, Mollitt DL, Pieper P: Pediatric cervical spine injuries: defining the disease. J Pediatr Surg 36:373376, 2001

46. Powers B, Miller MD, Kramer RS, Martinez S, Gehweiler JA Jr: Traumatic anterior atlanto-occipital dislocation. Neurosurgery 4:12-17, 1979

47. Rajasekaran S, Kanna PR, Shetty AP: Safety of cervical pedicle screw insertion in children: a clinicoradiological evaluation of computer-assisted insertion of 51 cervical pedicle screws including 28 subaxial pedicle screws in 16 children. Spine (Phila Pa 1976) 37:E216-E223, 2012

48. Rekate HL, Theodore N, Sonntag VK, Dickman CA: Pediatric spine and spinal cord trauma. State of the art for the third millennium. Childs Nerv Syst 15:743-750, 1999

49. Rodgers WB, Coran DL, Kharrazi FD, Hall JE, Emans JB: Increasing lordosis of the occipitocervical junction after arthrodesis in young children: the occipitocervical crankshaft phenomenon. J Pediatr Orthop 17:762-765, 1997

50. Rojas CA, Bertozzi JC, Martinez CR, Whitlow J: Reassessment of the craniocervical junction: normal values on CT. AJNR Am J Neuroradiol 28:1819-1823, 2007

51. Sawin PD, Traynelis VC, Menezes AH: A comparative analysis of fusion rates and donor-site morbidity for autogeneic rib and iliac crest bone grafts in posterior cervical fusions. $\mathbf{J}$ Neurosurg 88:255-265, 1998

52. Schultz KD Jr, Petronio J, Haid RW, Rodts GE, Erwood SC, Alexander J, et al: Pediatric occipitocervical arthrodesis. A review of current options and early evaluation of rigid internal fixation techniques. Pediatr Neurosurg 33:169-181, 2000

53. Sun PP, Poffenbarger GJ, Durham S, Zimmerman RA: Spectrum of occipitoatlantoaxial injury in young children. J Neurosurg 93 (1 Suppl):28-39, 2000
54. Theodore N, Aarabi B, Dhall SS, Gelb DE, Hurlbert RJ, Rozzelle CJ, et al: The diagnosis and management of traumatic atlanto-occipital dislocation injuries. Neurosurgery 72 (Suppl 2):114-126, 2013

55. Vitzthum HE, Dalitz K: Analysis of five specific scores for cervical spondylogenic myelopathy. Eur Spine J 16:20962103, 2007

56. Wholey MH, Bruwer AJ, Baker HL Jr: The lateral roentgenogram of the neck; with comments on the atlanto-odontoidbasion relationship. Radiology 71:350-356, 1958

57. Yamazaki M, Akazawa T, Koda M, Okawa A: Surgical simulation of instrumented posterior occipitocervical fusion in a child with congenital skeletal anomaly: case report. Spine (Phila Pa 1976) 31:E590-E594, 2006

58. Yerramneni VK, Chandra PS, Kale SS, Lythalling RK, Mahapatra AK: A 6-year experience of 100 cases of pediatric bony craniovertebral junction abnormalities: treatment and outcomes. Pediatr Neurosurg 47:45-50, 2011

\section{Disclosures}

The authors report no conflict of interest concerning the materials or methods used in this study or the findings specified in this paper.

\section{Author Contributions}

Conception and design: Theodore, Martinez-del-Campo, Kalb. Acquisition of data: Martinez-del-Campo. Analysis and interpretation of data: Martinez-del-Campo. Drafting the article: Martinez-del-Campo. Critically revising the article: Theodore, Turner, Rangel-Castilla, Soriano-Baron, Kalb. Reviewed submitted version of manuscript: Theodore. Statistical analysis: Martinez-delCampo. Study supervision: Theodore.

\section{Correspondence}

Nicholas Theodore, c/o Neuroscience Publications, Barrow Neurological Institute, St. Joseph's Hospital and Medical Center, 350 W Thomas Rd., Phoenix, AZ 85013. email: neuropub@ dignityhealth.org. 